\title{
Abnormalities in intestinal electrolyte transport in congenital chloridorrhoea
}

\author{
LESLIE A. TURNBERG \\ From The Royal Infirmary, Manchester
}

SUMMARY An investigation of small intestinal electrolyte transport was performed in a subject with congenital chloridorrhoea using a constant perfusion technique. The results indicate that the diarrhoea was not due to an abnormally high rate of secretion of fluid into the duodenum, and transport of electrolytes and glucose was normal in the jejunum. In contrast there was a marked abnormality of electrolyte transport in the ileum, chloride, sodium, and water entering the lumen and bicarbonate being absorbed in the absence of any concentration gradients for these ions. This is clearly different from the finding in normal subjects of sodium chloride and water absorption and bicarbonate secretion.

It is suggested that the likely prime mechanism for these abnormalities is a chloride/bicarbonate exchange acting in the direction of chloride secretion, that is, in the opposite direction to the normal anion exchange. The hydrogen ion gradient set up by this exchange could have induced a secondary reversal of the normal sodium/hydrogen exchange so that hydrogen was absorbed and sodium secreted.

From an analysis of the stool electrolyte concentrations and the rectal electrical potential difference it is suggested that in the colon chloride was secreted and bicarbonate absorbed against electrochemical gradients. Here too a reversed chloride/bicarbonate exchange is possibly responsible for the composition of the faecal electrolytes. As evidenced by the low faecal sodium concentration and the normal rectal potential difference, sodium transport is probably normal in the colon.

In 1945, Gamble and his co-workers (Gamble, Fahey, Appleton, and MacLachlan, 1945), and Darrow (1945) simultaneously described two children with an unusual form of severe diarrhoea. This disease was associated with a metabolic alkalosis in contrast to the more usual acidosis of severe diarrhoea. More striking was the observation that the concentration of chloride ions in the faeces of these patients was excessively high resulting in a uniquely different pattern of faecal electrolyte concentrations from that in normal subjects or in others with diarrhoea. The finding of a stool chloride concentration higher than the sum of the sodium and potassium concentrations has served as the most useful diagnostic indicator of this disorder since that time (Darrow, Pratt, Flett, Gamble, and Wiese, 1949). This feature has also led to the suggestion that a specific defect in chloride ion transport is responsible for the intestinal disease (Evanson and Stanbury, 1965).

Received for publication 3 May 1971.
This is the first instance in which an inborn error of metabolism has been held responsible for a defective intestinal transport of electrolytes and a study of such patients could shed light on normal mechanisms of transport. Unfortunately, attempts at direct investigation have been few, both because of the rarity of the disease and because of its association with a high mortality rate in infancy. Advantage was thus taken of an opportunity, which recently presented itself, to investigate a patient with chloridorrhoea who had survived into adolescence. Direct measurements of electrolyte transport rates were made in the jejunum and ileum of this patient using a perfusion technique.

\section{Clinical History}

Patient M.S., now 15 years old, had full metabolic balance studies performed when he was 8 years old and these were reported in detail by Evanson and Stanbury (1965). Since the history up to that time 
was fully described then only an outline is given here. He was the second child of unrelated parents and his two siblings had both suffered with diarrhoea from birth and died in infancy from its effects. Labour was induced at the 36th week following the onset of acute hydramnios, the birth weight being $3 \cdot 1 \mathrm{~kg}(6 \cdot 8 \mathrm{lb})$. He had a hare lip and cleft soft palate and developed marked neonatal jaundice. Since birth he had never been known to pass a formed stool and his childhood was punctuated by frequent prolonged admissions to hospital because of episodes of severe diarrhoea, occasionally associated with vomiting and dehydration. Conventional investigation of the alimentary tract revealed no abnormality but he was found to have a metabolic alkalosis and subnormal plasma levels of chloride and potassium. Following investigation in 1964, he was placed on a low-sodium chloride diet and given oral potassium supplements. His stool frequency was reduced from 10-14/day to 2-5/day and for the first time in his life he passed a formed stool. He gained weight and height and his general well-being was markedly improved. In the six-year interval since that time he has continued in reasonable health and on readmission on 10 January 1970 was $179 \mathrm{~cm}\left(5 \mathrm{ft} 10 \frac{1}{2} \mathrm{in}\right.$.) tall and weighed $51.5 \mathrm{~kg}(8 \mathrm{st} 1 \mathrm{lb})$. He was readmitted to hospital following an exacerbation of his diarrhoea, his stool frequency increasing from 2-3/day to 8-9/day, the stools being very fluid and brown in colour. He had vomited several times during the few days before admission.

On admission he was noted to be an intelligent, tall, thin boy with signs of moderate dehydration. His pulse rate was $76 / \mathrm{min}$ and blood pressure $120 / 90 \mathrm{~mm} \mathrm{Hg}$ and there were no abnormal signs in any system. Investigation revealed a serum sodium level of 140 , potassium 3.0 , chloride 86 , and 'bicarbonate' 35 m-equiv/l. Haemoglobin was $17.5 \mathrm{~g} / 100$ $\mathrm{ml}$, PCV $52 \%$, capillary blood $\mathrm{pH} 7 \cdot 48$.

He was treated with a diet low in sodium chloride (60 m-equiv/day) and given oral $\mathrm{K}+$ supplements to combat his deficit. On this regime he went into a strong positive balance of potassium and by the time of his discharge the diarrhoea had settled to two or three semi-formed motions per day. In- testinal perfusion studies were performed when he had recovered from his metabolic alkalosis and the diarrhoea had largely resolved. Towards the end of these investigations, involving perfusion for six hours on each of two days, he had an exacerbation of diarrhoea and alkalosis probably provoked by the infused salt solutions. These symptoms settled again within a few days.

\section{Investigations}

Intestinal perfusion was performed using the triplelumen tube technique described in detail by Cooper, Levitan, Fordtran, and Inglefinger (1966). Briefly, this technique involves the constant infusion of test solutions into the intestine and intestinal contents are sampled 10 and $40 \mathrm{~cm}$ distal to the point of infusion. In this way a $30-\mathrm{cm}$ length of intestine is studied and the problems of contamination with secretions from the intestine proximal to the test segment and reflux of perfusate proximally are largely eliminated. The tube was sited radiologically first in the jejunum so that the infusion point was at the duodenojejunal junction $(90 \mathrm{~cm}$ from the teeth), and the $30 \mathrm{~cm}$ test segment lay beyond this point in the upper jejunum. For studies in the ileum, the tube was allowed to move on in the intestine after the jejunal studies and the infusion point was sited $200 \mathrm{~cm}$ from the teeth. Perfusions were performed in the morning after a 12-hour fast.

The infusion rate was $9.5 \mathrm{ml} /$ minute for all studies except for certain of the ileal tests. Infusion solutions were made up as shown in Table I. All solutions contained polyethylene glycol, $5 \mathrm{~g} / \mathrm{l}$, as a non-absorbable marker.

The results of these tests were compared with those obtained in a group of normal subjects tested in a similar manner previously (Fordtran, Rector, and Carter, 1968; Turnberg, Bieberdorf, Morawski, and Fordtran, 1970a; Turnberg, Fordtran, Carter, and Rector, 1970b).

The electrical potential difference was measured between the rectum and abraded skin using a Beckman silver/silver chloride electrode surrounded by agar gel made up in $3 \mathrm{M}$ potassium chloride and

\begin{tabular}{|c|c|c|c|c|c|c|c|c|}
\hline & Solution & $\mathrm{NaCl}$ & $\mathrm{NaHCO}_{3}$ & $K C I$ & Glucose & Mannitol & $\mathrm{Na}_{2} \mathrm{SO}_{4}$ & $\mathrm{~K}_{2} \mathrm{SO}_{4}$ \\
\hline \multirow[t]{3}{*}{ Jejunum } & 1 & 140 & - & - & - & - & - & - \\
\hline & 2 & 100 & 35 & 5 & - & - & - & - \\
\hline & 3 & 120 & - & - & 80 & - & - & - \\
\hline \multirow[t]{3}{*}{ Ileum } & 1 & 100 & 30 & 5 & - & - & - & - \\
\hline & 2 & 50 & - & 5 & - & 150 & - & - \\
\hline & 3 & - & 30 & - & - & 50 & 100 & 5 \\
\hline
\end{tabular}

Table I Constituents of infusion solutions ${ }^{1}$ 
placed in a porous bag filled with electrode jelly. This was sited in the rectum $10 \mathrm{~cm}$ from the anal margin through a sigmoidoscope. A similar reference electrode was placed on the abraded skin of the forearm. The potential difference measured between these two electrodes when placed in a beaker of saline was subtracted from the measured rectal/skin potential difference.

\section{Results}

\section{JEJUNUM}

The volume of fasting secretion entering the test segment from the duodenum was estimated from the measured dilution of infusate between the infusion point and the proximal aspiration site and was found to be 1.0 to $1.4 \mathrm{ml}$ per minute. Thus there was no evidence for an excessive volume of resting endogenous secretion from the pancreas, liver, or stomach.

Previous investigations have suggested that chloride transport in the normal jejunum is entirely passive and chloride ions are distributed across jejunal mucosa according to electrochemical gradients. A wide range of results for chloride movement was found in normal subjects during jejunal perfusion with isotonic saline, and the mean value of $4.9 \mathrm{~m}$-equiv/hour absorbed is similar to that of $3.2 \mathrm{~m}$-equiv/hour found in this subject with chloridorrhoea. Chloride movement from the bicarbonatesaline was $2.2 \mathrm{~m}$-equiv/hour secreted ${ }^{1}$ in this patient which is again within the range found in normal subjects (Table II).

Net absorption of sodium and water occurred from each of the three solutions used to perfuse the jejunum. An absorptive rate for water of $33 \mathrm{ml} /$ hour

'The terms 'secretion' and 'absorption' are used in the wide sense in this paper to indicate the net accumulation within the lumen or net removal from the lumen of electrolytes. with 'isotonic' saline, $37 \mathrm{ml} /$ hour with 'bicarbonate saline', and $108 \mathrm{ml} /$ hour with 'glucose saline' was achieved. In normal subjects it has been shown that absorption of sodium from isotonic saline is variable and usually slight, while its absorption is enhanced by the addition of bicarbonate or glucose to the luminal fluid (Table II) (Fordtran et al, 1968). This patient absorbed sodium from isotonic saline at a rate of $6.6 \mathrm{~m}$-equiv/hour, and bicarbonate did not appear to increase further its absorption $(6.8 \mathrm{~m}$ equiv/hour). However, while bicarbonate did not enhance sodium absorption, the amounts absorbed with or without bicarbonate were within the normal range. It is doubtful if this represents a significant abnormality since absorption of bicarbonate itself was similar to normal: $6 \cdot 1 \mathrm{~m}$-equiv/hour compared with a mean of 5.9 m-equiv/hour in a normal group. Glucose increased sodium absorption to 9.3 m-equiv/ hour, a result similar to that in normal subjects. Glucose itself was absorbed at a slower rate than the mean of a normal group although this was still within the normal range. The mean concentration of glucose in the test segment $(33.5 \mathrm{mM})$ was lower than that in the normal group (45 mM) which may account for the slightly lower rate of glucose absorption.

\section{ILEUM}

\section{Absorption against a gradient}

The normal ileum absorbs both sodium and chloride against a considerable electrochemical gradient (Turnberg et al, 1970a). The ability to absorb these ions against a concentration gradient was studied in this subject by infusing a solution with a low concentration of sodium chloride at $50 \mathrm{~m}$-equiv/l. This was made isotonic with plasma by the addition of mannitol. In contrast with the normal ileum, which can absorb chloride until the luminal concentration

\begin{tabular}{|c|c|c|c|c|c|}
\hline \multirow[b]{2}{*}{ Solution Perfused } & \multirow[b]{2}{*}{ Ion } & \multicolumn{4}{|c|}{ Absorption/Secretion } \\
\hline & & \multicolumn{3}{|c|}{ Normal } & $M . S$. \\
\hline $\begin{array}{l}\text { Isotonic saline } \\
\text { Bicarb./saline } \\
\text { Glucose/saline } \\
\text { Bicarb./saline } \\
\text { Glucose/saline } \\
\text { Isotonic saline } \\
\text { Bicarb./saline }\end{array}$ & $\begin{array}{l}\mathrm{Na}^{+} \\
\mathrm{Na}^{+} \\
\mathrm{Na}^{+} \\
\mathrm{HCO}_{3}^{-} \\
\mathrm{Glucose}^{-} \\
\mathrm{Cl}^{-} \\
\mathrm{Cl}^{-}\end{array}$ & $\begin{array}{r}14 \\
14 \\
5 \\
8 \\
5 \\
14 \\
8\end{array}$ & $\begin{array}{r}-3.4 \\
-9.5 \\
-8.1 \\
-5.9 \\
-17.4 \\
-4.9 \\
-2.8\end{array}$ & $\begin{array}{l}+4.8 \text { to }-11.2 \\
+2.0 \text { to }-19 \\
-4.4 \text { to }-9.4 \\
-3.0 \text { to }-10 \\
-10.7 \text { to }-31.1 \\
+4.8 \text { to }-13.7 \\
+6.5 \text { to }-8.0\end{array}$ & $\begin{array}{r}-6 \cdot 6 \\
-6 \cdot 8 \\
-9 \cdot 3 \\
-6 \cdot 1 \\
-11 \cdot 2 \\
-3 \cdot 2 \\
+2 \cdot 2\end{array}$ \\
\hline
\end{tabular}

Table II Ion movements during perfusion of the jejunum in normal subjects compared with patient M.S. ${ }^{1}$

${ }^{1}$ The figures are in m-equiv or mM transported per hour per $30 \mathrm{~cm}$ of jejunum. + Sign indicates net 'secretion'; - sign indicates net 'absorption'; $\boldsymbol{n}=$ number of normal subjects tested. The data obtained in the normal subjects are derived from previous work, some of which has been reported elsewhere (Fordtran, Rector, and Carter, 1968; Turnberg, Fordtran, Carter, and Rector, 1970). 
is as low as $15 \mathrm{~m}$-equiv/l, in this patient chloride was secreted at a rate of $10.4 \mathrm{~m}$-equiv/hour when the mean luminal concentration was 84.5 m-equiv/ 1 (Table III). Sodium too entered the lumen at a rate of $7.4 \mathrm{~m}$-equiv/hour when the mean luminal concentration of sodium was $86 \mathrm{~m}$-equiv/l. This also is abnormal since the normal ileum can absorb sodium from solutions containing as little as $30 \mathrm{~m}$-equiv/l. It is notable that sodium entered the lumen at a slower rate than chloride $(7.4 \mathrm{~m}$-equiv/hour compared with 10.4 m-equiv/hour respectively) despite the fact that the concentration gradient between plasma and ileal lumen was greater for sodium than for chloride (140 m-equiv/l in plasma and $86 \mathrm{~m}$-equiv/l in the lumen for sodium and $90 \mathrm{~m}$-equiv/ 1 in plasma and $85 \mathrm{~m}$-equiv/l in the lumen for chloride). Factors in addition to the concentration gradients must therefore have influenced the relative movement of these ions across the ileal mucosa. Water was secreted at a rate of $51.6 \mathrm{ml} / \mathrm{min}$, as a passive consequence of the net secretion of ions.

In order to study the interrelationship between electrolyte movements a little more closely a plasmalike electrolyte solution was perfused slowly through the ileal lumen $(3.0 \mathrm{ml} / \mathrm{min})$ (Table III). Again sodium and chloride entered the lumen while bicarbonate was absorbed, the opposite to that in the normal ileum where absorption of sodium and chloride and secretion of bicarbonate usually occurs (Turnberg et al, 1970a). Chloride again entered the lumen at a greater rate than sodium, $9 \cdot 4 \mathrm{~m}$-equiv/hour compared with $7 \mathrm{~m}$-equiv/hour. The chloride con- centration in the lumen at the distal end of the test segment, 129 m-equiv/l, was higher than the plasma level, while the bicarbonate concentration, 8.4 m-equiv $/ 1$, was lower than the plasma concentration. These concentration changes are in the opposite direction to those found in the normal ileum (Bucher, Flynn, and Robinson, 1944).

\section{$\mathrm{p} H$ changes}

With absorption of bicarbonate from the plasmalike electrolyte solution the perfusate became more acid as it passed down the ileal lumen (Table IV), in contrast to the slight rise in $p \mathrm{H}$ which occurs in normal subjects. However, in the normal ileum the perfusate can be made to become more acid if it is modified by replacing chloride with the nonabsorbable anion, sulphate. These findings suggest that the ileum in this patient responded by changing the $p \mathrm{H}$ of the perfusate as if chloride were a nonabsorbable anion.

In M.S. a more profound fall in $p H$ than in normal subjests was noted with the sulphate solution (Table IV).

\section{Potential difference}

The electrical potential difference between the rectal lumen and the abraded skin of the forearm was measured in this patient on two occasions, the first shortly after admission to hospital when the patient was markedly alkalotic and suffering from electrolyte imbalance and the second when his acid-base and electrolyte deficiencies had been improved. The

\begin{tabular}{|c|c|c|c|c|c|c|c|c|c|c|c|c|c|}
\hline \multirow[t]{2}{*}{ Solution } & \multirow[t]{2}{*}{$\begin{array}{l}\triangle \mathrm{H}_{2} \mathrm{O} \\
\quad(\mathrm{ml} / \mathrm{hr})\end{array}$} & \multicolumn{2}{|c|}{$\begin{array}{l}\left(\mathrm{Na}^{+}\right) \\
(\mathrm{m} \text {-equiv/l) }\end{array}$} & \multirow{2}{*}{$\begin{array}{l}\Delta N a \\
(m- \\
\text { equiv/hr) }\end{array}$} & \multicolumn{2}{|c|}{$\begin{array}{l}\left(\mathrm{Cl}^{-}\right) \\
(\mathrm{m} \text {-equiv/l) }\end{array}$} & \multirow{2}{*}{$\begin{array}{l}\Delta \mathrm{Cl}^{-} \\
(\mathrm{m}- \\
\text { equiv/hr) }\end{array}$} & \multicolumn{2}{|c|}{$\begin{array}{l}\left(K^{+}\right) \\
(m-e q u i v / l)\end{array}$} & \multirow{2}{*}{$\begin{array}{l}\Delta K^{+} \\
(m- \\
\text { equiv/hr) }\end{array}$} & \multicolumn{2}{|c|}{$\begin{array}{l}\left(\mathrm{HCO}_{3}^{-}\right) \\
(\mathrm{m} \text {-equiv/l) }\end{array}$} & \multirow{2}{*}{$\begin{array}{l}\triangle \mathrm{HCO}_{3}- \\
(\mathrm{m}- \\
\text { equiv/hr) }\end{array}$} \\
\hline & & $\begin{array}{l}\text { Proxi- } \\
\text { mal }\end{array}$ & Distal & & $\begin{array}{l}\text { Proxi- } \\
\text { mal }\end{array}$ & Distal & & $\begin{array}{l}\text { Proxi- } \\
\text { mal }\end{array}$ & Distal & & $\begin{array}{l}\text { Proxi- } \\
\text { mal }\end{array}$ & Distal & \\
\hline $\begin{array}{l}\text { Plasma-like (1) } \\
\text { 'Low' } \mathrm{NaCl} \text { (2) }\end{array}$ & $\begin{array}{l}+56.4 \\
+51.6\end{array}$ & $\begin{array}{r}129 \cdot 2 \\
83 \cdot 5\end{array}$ & $\begin{array}{c}128 \cdot 3 \\
88\end{array}$ & $\begin{array}{l}+7 \\
+7 \cdot 4\end{array}$ & $\begin{array}{r}120 \\
80\end{array}$ & $\begin{array}{r}129 \\
89\end{array}$ & $\begin{array}{r}+9.4 \\
+10.4\end{array}$ & $\begin{array}{l}5 \cdot 4 \\
4 \cdot 0\end{array}$ & $\begin{array}{l}4 \cdot 9 \\
3 \cdot 8\end{array}$ & $\begin{array}{l}+0.16 \\
+0.06\end{array}$ & $\begin{array}{l}19 \cdot 7 \\
4 \cdot 3\end{array}$ & $\begin{array}{l}8 \cdot 4 \\
1 \cdot 2\end{array}$ & $\begin{array}{l}-2 \cdot 23 \\
-2 \cdot 04\end{array}$ \\
\hline
\end{tabular}

Table III Ileal studies in chloridorrhoea ${ }^{1}$

${ }^{1}$ Concentration of ions at the proximal and distal ends of the test segment of ileum are shown and the amounts of each absorbed or secreted per hour. + Sign indicates secretion, - sign indicates absorption. Solution 1 was infused at $3.0 \mathrm{ml} / \mathrm{min}$ and solution 2 at $9.5 \mathrm{ml} / \mathrm{min}$.

\begin{tabular}{lllll}
\hline Solution & $\mathrm{pH}$ & & \\
\cline { 2 - 4 } & $\mathrm{M} . \mathrm{S}$. & \multicolumn{2}{c}{ Six Normal Subjects } \\
\cline { 2 - 4 } & Proximal Aspiration Site & Distal Aspiration Site & Proximal Aspiration Site & Distal Aspiration Site \\
\hline Bicarbonate/saline & $7 \cdot 12$ & $6 \cdot 86$ & $7 \cdot 39$ & $7 \cdot 45$ \\
Sulphate (chloride free) & $6 \cdot 67$ & $6 \cdot 26$ & $7 \cdot 16$ & $7 \cdot 11$ \\
\hline
\end{tabular}

Table IV Change in $\mathrm{pH}$ of perfusate during passage from the proximal to the distal end of the 30 -cm test segment of ileum in patient M.S. and mean values in six normal subjects ${ }^{1}$

${ }^{1}$ The solutions in M.S. were infused at $3.0 \mathrm{ml} / \mathrm{min}$ and in the normal subjects at $9.5 \mathrm{ml} / \mathrm{min}$. 
initial potential difference was markedly elevated to $75 \mathrm{mV}$, and on the second occasion 11 days later was $20 \mathrm{mV}$ (lumen negative on both occasions). The small intestinal perfusion studies were performed shortly after the second of these measurements. The second measurement produced values similar to those reported in normal subjects and the first resembles values found after the administration of aldosterone to normal subjects (Edmonds and Godfrey, 1970).

\section{Stool electrolytes}

The concentrations of electrolytes in the stools were measured using techniques already described (Evanson and Stanbury, 1965). The results were similar to those reported previously for this patient (Table V). Sodium and potassium concentrations were within the range reported in normal subjects by Wrong, Metcalf-Gibson, Morrison, $\mathrm{Ng}$, and Howard (1965), using dialysis bags. Chloride concentration was markedly greater than normal, while the bicarbonate concentration was less than normal.

\section{Discussion}

With the development in recent years of intubation and perfusion techniques for studying intestinal transport in vivo in human subjects it has been possible to characterize the normal mechanisms for electrolyte transport. On the basis of this knowledge it is now possible to make meaningful measurements of electrolyte movement in the intestine of patients suffering from diarrhoea, and advantage was taken of these techniques to study this patient.

The uniqueness of the abnormal stool electrolyte pattern in congenital chloridorrhoea has prompted the suggestion that the disease is due to a specific inborn defect in intestinal electrolyte transport (Evanson and Stanbury, 1965). The two most obvious abnormalities are the very high chloride ion concentration in the stools and the metabolic alkalosis and any description of the mechanisms involved should explain these features of the disease.

Theoretical possibilities for the excessive loss of chloride are either a failure of the normal process for intestinal absorption of chloride ions or a secretion into the intestine of a chloride-containing fluid. Such a secretion could theoretically arise from the stomach, the liver, the pancreas, or from the intestinal mucosa, and would have to be excessive enough to overwhelm the capacity of a presumably normally absorbing intestine. An attempt was made to assess these possibilities in the present investigations.

The low rate of contamination by fasting secretions entering the jejunal test segment from the more proximal bowel suggests that an excessive secretion from stomach, pancreas, or liver was not causing the chloridorrhoea. Theoretically too it is difficult to imagine the constitution of a secretion entering high in the intestinal tract which, when modified by a normal distal bowel, still emerges in a stool with so gross a derangement of the electrolyte composition.

Since the normal process by which chloride ions are transported across the jejunal mucosa appears to be entirely passive (Fordtran et al, 1968) and presumably, therefore, does not require a specific transport system, it is not surprising that no abnormality in jejunal chloride transport was detected in this subject. The normal absorption of sodium, bicarbonate, and glucose suggests that jejunal transport mechanisms were not markedly impaired.

In contrast, water and electrolyte movement in the ileum was clearly abnormal. The normal ileum absorbs sodium and chloride against electrochemical gradients and secretes bicarbonate (Turnberg et al, 1970a). In this patient there was not only a failure to absorb sodium and chloride against a concentration gradient but also evidence of secretion of sodium and chloride into the lumen and absorption of bicarbonate in the absence of any concentration gradients for these ions.

From a detailed analysis of ionic movement interrelationships in normal subjects it has been suggested that ileal ion transport is explicable in terms of a simple model (Fig. 1a) (Turnberg et al, 1970a). A double (cation and anion) exchange process, in which absorption of a sodium ion is accomplished in exchange for secretion of a hydrogen ion and in

\begin{tabular}{|c|c|c|c|c|c|c|c|c|}
\hline & \multicolumn{2}{|c|}{ Sodium } & \multicolumn{2}{|c|}{ Potassium } & \multicolumn{2}{|c|}{ Chloride } & \multicolumn{2}{|c|}{ Bicarbonate } \\
\hline & Mean & Range & Mean & Range & Mean & Range & Mean & Range \\
\hline $\begin{array}{l}\text { Patient } \\
\text { Normal }\end{array}$ & $\begin{array}{l}40 \cdot 6 \\
31 \cdot 6\end{array}$ & $\begin{array}{l}5-85 \\
4 \cdot 4-112\end{array}$ & $\begin{array}{l}61 \cdot 8 \\
75\end{array}$ & $\begin{array}{l}46-86 \\
29-147\end{array}$ & $\begin{array}{r}129.0 \\
16.0\end{array}$ & $\begin{array}{c}94-172 \\
5-38\end{array}$ & $\begin{array}{r}5 \\
40\end{array}$ & $\begin{array}{l}2-10 \\
4-66\end{array}$ \\
\hline
\end{tabular}

Table V Faecal electrolyte concentrations in the patient with chloridorrhoea compared with normal values derived from Wrong et al (1965) 1

${ }^{1}$ The values (m-equiv/l) for the patient were obtained for 28 total daily faecal collections. During this time he was maintained on a diet containing $60 \mathrm{~m}$-equiv/day of sodium chloride. 

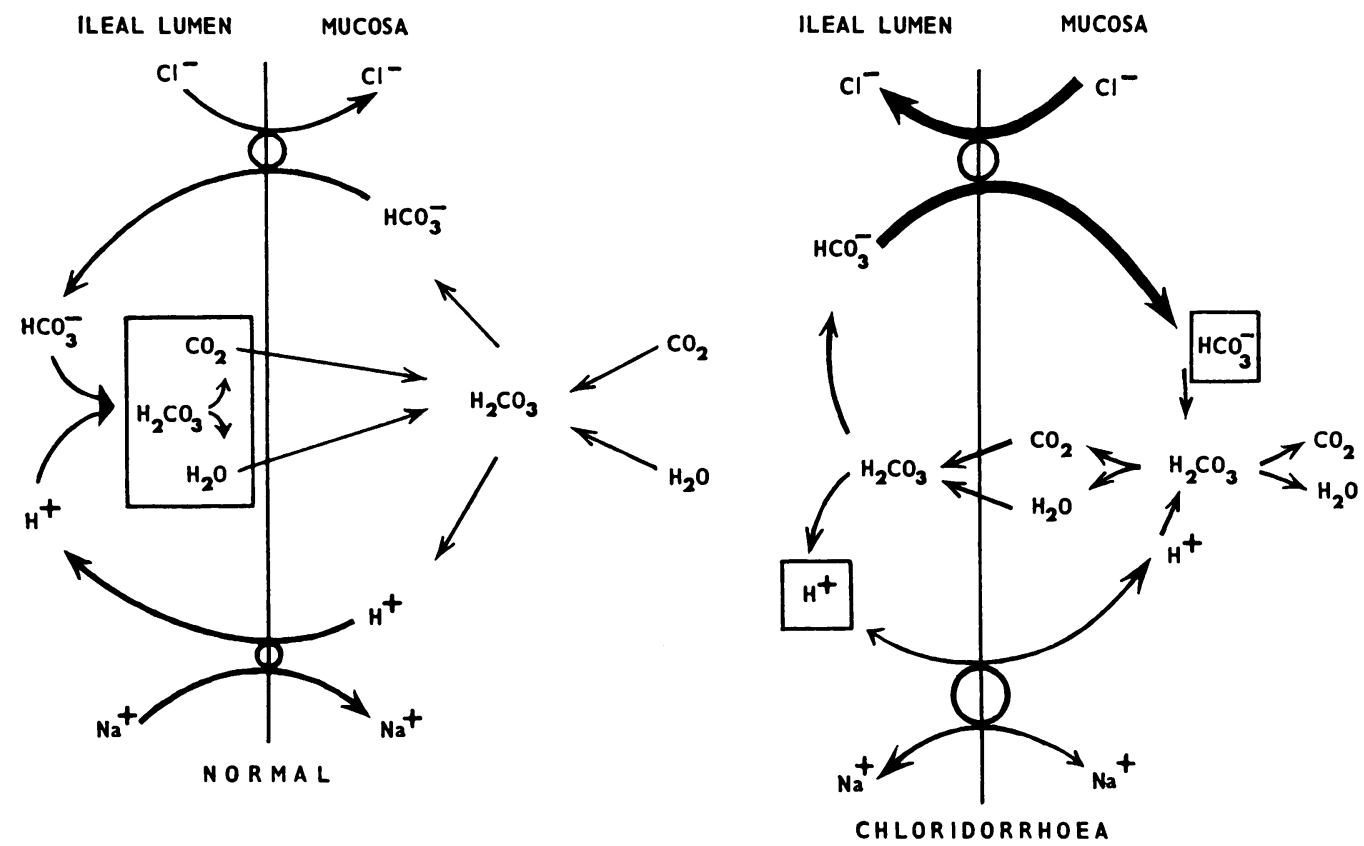

Fig. 1 A model for ion transport in the ileum. A, in the normal subject (after Turnberg, Bieberdorf, Morawski, and Fordtran, 1970), and B, in the patient with chloridorrhoea. Note, in $B$, that the $\mathrm{H}^{+}$ion concentration gradient, the lumen having a higher concentration than the mucosa, is set up by transport of $\mathrm{HCO}_{3}^{-}$from lumen to mucosa. This $\mathrm{H}^{+}$concentration gradient will tend to oppose the normal $\mathrm{Na}^{+} / \mathrm{H}^{+}$exchange and force $\mathrm{Na}^{+}$ secretion through reversal of the exchange.

which chloride ions are absorbed in exchange for secreted bicarbonate ions, provided a reasonable interpretation of all the experimental observations on movement of these ions. According to this scheme, absorption of sodium and chloride is accompanied by secretion of hydrogen and bicarbonate. The secreted hydrogen and bicarbonate react in the lumen to form $\mathrm{CO}_{2}$ and water which then diffuse out. The relative amounts of the secreted hydrogen and bicarbonate ions determine the final concentration of bicarbonate in luminal fluid. As a rule more chloride than sodium is absorbed, more bicarbonate is secreted than hydrogen, the net result being an accumulation of bicarbonate in the lumen or bicarbonate 'secretion'. It is possible to discuss the abnormalities seen in this patient on the basis of this model for ion transport.

If the chloride/bicarbonate exchange system was inactive then one would expect chloride to be neither absorbed nor secreted when no electrochemical gradient existed between extracellular fluid and ileal lumen. The findings here suggest that the chloride/bicarbonate system was not merely inactive but working in a direction opposite to normal against a concentration gradient for these ions, at least at the time of this study.

Recent experiments have shown that active chloride secretion can be induced in isolated strips of normal human ileum by cholera exotoxin and by theophylline (Al-Awqati, Cameron, Field, and Greenhough, 1970), and experiments in animals also suggest that chloride may be actively secreted in the normal intestine under certain circumstances (Tidball, 1961; Powell, Malawer, and Plotkin, 1968).

That chloride secretion and bicarbonate absorption can be provoked in normal subjects by varying the concentration of these anions in the intestinal perfusate suggests that the anion exchange is normally potentially reversible (Turnberg et al, 1970a). Alternatively, activation of a separate anion exchange working in the direction of chloride secretion under these specific conditions could explain this effect. Whichever is responsible it is clear that the normal human ileum seems capable, under certain conditions, of secreting chloride and absorbing bicarbonate. In this patient with chloridorrhoea 
the 'reversed' anion exchange appeared to predominate.

Sodium absorption could be secondarily affected by this reversed anion exchange as follows. Bicarbonate and hydrogen ions in the lumen are in equilibrium with carbonic acid which in turn is in equilibrium with carbon dioxide in water:

$\mathrm{HCO}_{3}^{-}+\mathrm{H}^{+} \rightleftharpoons \mathrm{H}_{2} \mathrm{CO}_{3} \rightleftharpoons \mathrm{CO}_{2}+\mathrm{H}_{2} \mathrm{O}$.

Absorption of bicarbonate ions through a reversed $\mathrm{Cl} / \mathrm{HCO}_{3}{ }^{-}$exchange will cause this state of equilibrium to move over to the left with dissociation of more carbonic acid and leaving an excess of $\mathrm{H}^{+}$ ions in the lumen. Within the mucosal cell the absorbed bicarbonate ions will tend to push a similar state of equilibrium over to the right forming more carbonic acid and removing $\mathrm{H}^{+}$ions in the process. A concentration gradient for $\mathrm{H}^{+}$ions would thus be set up across the mucous membrane with a high concentration in the lumen and a low one within the mucosa. The direction of the $\mathbf{H}^{+}$concentration gradient would oppose entry of $\mathrm{H}^{+}$ions from the mucosa through a normally acting $\mathrm{Na}^{+} / \mathrm{H}^{+}$exchange. If the $\mathrm{H}^{+}$concentration in the lumen were high enough it could induce movement of $\mathrm{H}^{+}$ions in the opposite direction-from the lumen into the mucosa. It is possible that $\mathrm{H}^{+}$ions traversing the mucosa from lumen to mucosal cell could force sodium movement into the lumen through a reversed $\mathrm{Na}^{+} / \mathrm{H}^{+}$exchange. (Here it is necessary to postulate that the cation exchange is reversible too or can be shut off and a separate cation exchange be activated in the direction opposite to normal.) That the secretion of sodium in this case was secondary to a $p \mathrm{H}$ gradient set up in this way by bicarbonate absorption is supported by the finding that the luminal $p \mathrm{H}$ became acid during perfusion in contrast to the normal which becomes more alkaline. The observation that more chloride was secreted than sodium also supports the suggestion that in our patient a defect in chloride transport is the primary abnormality and that the sodium transport disorder is a secondary phenomenon. If a primary defect in sodium transport, with a secondary effect on the chloride/bicarbonate exchange, was responsible for the findings here more sodium than chloride should have been secreted and the lumen should have become more alkaline.

Explanations of the experimental observations not based on a double ion exchange system are less satisfactory. An abnormal secretion of saline, for instance, should have resulted in sodium and chloride entering the lumen at a similar rate and a change in $p \mathrm{H}$ should not have been observed. The possibility that the observations were due to a dual abnormality in which sodium chloride was secreted and sodium bicarbonate absorbed cannot be ex- cluded but this explanation requires two coincident abnormalities. It thus appears most likely that the primary defect lay in a reversed chloride/bicarbonate exchange system which produced a secondary effect on the sodium/hydrogen exchange. The electrical potential difference across the ileal mucosal membrane should not be different from normal if this description is correct, since neither ion exchanges are electrogenic. Unfortunately, this could not be confirmed in this patient since it was not possible to measure the potential difference in the small bowel.

In the patient with chloridorrhoea studied by Pearson, Sladen, Edmonds, Wills, Tavill, and McIntyre (1970) there was no net movement of chloride into or out of the ileal lumen against a concentration gradient. It is possible that the results reported here differ from theirs because of a variation in activity of the chloride secretory process. Of 14 normal subjects in whom the ileum was studied, 13 absorbed sodium and chloride in varying amounts while one secreted these ions, emphasizing this variability of function of the ileum in vivo (Turnberg et al, 1970a).

Although the colon was not directly studied in this patient it is possible to draw some tentative conclusions from the stool electrolyte composition and from the electrical potential difference across the rectal mucosa. Both sodium and potassium concentrations in the stool were within the range found in normal subjects by Wrong et al (1965) while the chloride concentration was markedly higher than normal, and bicarbonate, when the patient was in metabolic balance, lower than normal. These findings hint again that a chloride/bicarbonate exchange may be active in a direction opposite to that postulated in the normal colon (Phillips, 1969; Devroede and Phillips, 1969). For the observed stool chloride concentrations of about $130 \mathrm{~m}$-equiv/l to be maintained passively against a plasma concentration of $90 \mathrm{~m}$ equiv/l the electrical potential difference would have to be orientated so that the lumen was positive to the serosa. The potential difference was $20 \mathrm{mV}$, after the patient's electrolyte imbalance was corrected, with the lumen negative. This is in the opposite direction to the potential required for a simple passive distribution of chloride. The high concentration of stool chloride maintained when the rectal potential difference was $75 \mathrm{mV}$, lumen negative, during a period of metabolic imbalance, is even more remarkable and is strong evidence for an active secretory process for chloride in the colon of this patient. An active chloride/bicarbonate exchange working in the direction of chloride secretion similar to that postulated in the ileum seems an acceptable explanation for the stool anion concentration. It should be emphasized that this conclusion is based 
on indirect evidence and direct measurements of electrolyte transport rates in the colon will be necessary for confirmation of these speculations.

Sodium is probably absorbed by an active, electrogenic, process unrelated to a sodium/hydrogen exchange in the normal colon. Under these circumstances sodium absorption should not be influenced to any great extent by variation in hydrogen ion concentration gradients across the mucosa as was discussed with regard to the ileum. Hence an abnormal chloride/bicarbonate exchange should have little effect on sodium movement here. The markedly elevated electrical potential difference found in this patient between the rectal lumen and skin was probably a secondary phenomenon, possibly due to hyperaldosteronism provoked by his plasma electrolyte changes (Edmonds and Godfrey, 1970). That this abnormal potential was not of prime importance in the causation of the disorder is evidenced by its return to normal levels when plasma electrolyte abnormalities were corrected. However, since the potential difference is thought to be produced predominantly by active transport of sodium (Curran and Schwartz, 1960; Edmonds and Godfrey, 1970) its normality suggests that sodium transport was also normal and apparently can be stimulated by salt-retaining hormones.

The diarrhoea in this patient can best be explained on the basis of an osmotic purgative effect of the secreted chloride ions accompanied by hydrogen ions. The hydrogen ions, derived from carbonic acid and remaining in the lumen when bicarbonate ions are absorbed, are probably excreted either as ammonium or as hydrogen.

The metabolic alkalosis so characteristic of this disease is also explicable in terms of a reversed chloride/bicarbonate exchange since bicarbonate is absorbed from the lumen in excess of normal and hydrogen ions are lost into the lumen. The hypokalaemia secondarily produced as a consequence of the diarrhoea must also play a part in the production of the alkalosis.

The nature of hypothetical exchange carriers on intestinal membranes is completely unknown but one may speculate on at least two ways in which the defect in chloridorrhoea could be produced. First, a reversal of the direction of transport by, for example, a change in the orientation of a protein transport molecule within the membrane could be responsible. Or secondly, a failure of activity of the normal anion exchange carrier could equally produce the abnormality if an exchange system moving ions in the opposite direction was then revealed. The reversed exchange is then visualized as being normally present but hidden by the more active chloride absorbing exchange. Much more knowledge of carrier proteins in general is required before the defect in congenital chloridorrhoea can be understood at the molecular level.

I am indebted to Professor S. W. Stanbury for his help and encouragement in this study of his patient. He generously provided me with the data on stool electrolyte measurements.

I am grateful to Mrs Maureen Dussart for her expert technical assistance.

This work was supported by a grant from the Board of Governors of the United Manchester Hospitals to whom I express my thanks.

\section{References}

Al-Awqati, Q., Cameron, J. L., Field, M., and Greenhough, W. B., III (1970). Response of human ileal mucosa to choleragen and theophylline. (Abstr.). J. clin. Invest., 49, 2 a.

Bucher, G. R., Flynn, J. C., and Robinson, C. S. (1944). The action of the human small intestine in altering the composition of physiological saline. J. biol. Chem., 155, 305-313.

Cooper, H., Levitan, R., Fordtran, J. S., and Ingelfinger, F. J. (1966). A method for studying absorption of water and solute from the human small intestine. Gastroenterology, 50, 1-7.

Curran, P. F., and Schwartz, C. F. (1960). Na, Cl, and water transport by rat colon. J. gen. Physiol., 43, 555-571.

Darrow, D. C. (1945). Congenital alkalosis with diarrhea. J. Pediat.. 26, 519-532.

Darrow, D. C., Pratt, E. L., Flett, J. Jr., Gamble, A. H., and Wiese, H. F. (1949). Disturbances of water and electrolytes in infantile diarrhoea. Pediatrics, 3, 129-156.

Devroede, G. J., and Phillips, S. F. (1969). Conservation of sodium, chloride and water by the human colon. Gastroenterology, 56, 101-109.

Edmonds, C. J., and Godfrey, R. C. (1970). Measurement of electrical potentials of the human rectum and pelvic colon in normal and aldosterone-treated patients. Gut, 11, 330-337.

Evanson, J. M., and Stanbury, S. W. (1965). Congenital chloridorrhoea or so-called congenital alkalosis with diarrhoea. Gut, 6, 29-38.

Fordtran, J. S., Rector, F. C., Jr., and Carter, N. W. (1968). The mechanisms of sodium absorption in the human small intestine. J. clin. Invest., 47, 884-900.

Gamble, J. L., Fahey, K. R., Appleton, J., and MacLachlan, E. (1945). Congenital alkalosis with diarrhoea. J. Pediat., 26, 509-518.

Pearson, A. J. G., Sladen, G. E., Edmonds, C. J., Wills, M. R., Tavill, A. S., and McIntyre, N. (1970). Congenital chloridorrhoea: The nature of the defect. (Abstr.) Gut, 11, 370.

Phillips, S. F. (1969). Absorption and secretion by the colon. Gastroenterology, 56, 966-971.

Powell, D. W., Malawer, S. J., and Plotkin, G. R. (1968). Secretion of electrolytes and water by the guinea pig small intestine in vivo. Amer. J. Physiol., 215, 1226-1233.

Tidball, C. S. (1961). Active chloride transport during intestinal secretion. Amer. J. Physiol., 200, 309-312.

Turnberg, L. A., Bieberdorf, F. S., Morawski, S. G., and Fordtran, J. S. (1970a). Interrelationship of chloride, bicarbonate, sodium and hydrogen transport in the human ileum. J. clin. Invest., 49, 557-567.

Turnberg, L. A., Fordtran, J. S., Carter, N. W., and Rector, F. C., Jr. (1970b). Mechanism of bicarbonate absorption and its relationship to sodium transport in the human jejunum. J. clin. Invest., 49, 548-556.

Wrong, O. M., Metcalf-Gibson, A., Morrison, R. B. I., Ng, S. T., and Howard, A. V. (1965). In vivo dialysis of faeces as a method of stool analysis. Clin. Sci., 28, 357-375. 